\title{
Babesiose canina: Revisão
}

\author{
Viviane Araujo Cassinoni Moreira Dias ${ }^{1}$ \& Fernanda Lúcia Alves Ferreira ${ }^{2 *}$ \\ IEstudante do curso de Medicina Veterinária da Universidade Anhanguera de São Paulo (UNIAN). São Bernardo do Campo \\ - SP. Brasil. E-mail: vivianecassinoni@hotmail.com \\ ${ }^{2}$ Professor Titular na Universidade Anhanguera de São Paulo (UNIAN). São Bernardo do Campo - SP. Brasil. E-mail: \\ falves@anhanguera.com \\ *Autor para correspondência
}

\begin{abstract}
RESUMO. A Babesiose é uma doença parasitária provocada pelo desenvolvimento de hematozoários do Gênero Babesia, destacando-se a Babesia canis e Babesia gibsoni, como principais espécies envolvidas em casos diagnosticados no Brasil. A transmissão ocorre durante o repasto sanguíneo de carrapatos Ixodídeos do Gênero Rhipicephalus quando o sangue contendo esporozoítos é inoculado no hospedeiro definitivo, os cães domésticos. O parasito invade as hemácias e se reproduz assexuadamente, causando hemólise intravascular. Dependendo da localização da Babesia, o animal pode apresentar desde uma anemia severa a um quadro de infarto cerebral. O objetivo do estudo é realizar uma breve revisão sobre babesiose canina, destacando pontos fundamentais na elucidação de casos clínicos característicos ou não na clínica de animais domésticos.
\end{abstract}

Palavras chave: Anemia hemolítica, Babesia spp., carrapato ixodídeo

\section{Canine babesiosis: Review}

\begin{abstract}
Babesiosis is a parasitic disease caused by the development of Babesia species, highlighting Babesia canis and Babesia gibsoni as main species involved in cases diagnosed in Brazil. Transmission occurs during blood feeding of Rhipicephalus ticks when blood containing sporozoites is inoculated in the definitive host, domestic dogs. The parasite invades red blood cells and reproduces asexually, causing intravascular hemolysis. Depending on the location of Babesia, dogs may display a severe anemia or a cerebral infarction. The objective of the study is to conduct a brief review of canine babesiosis, highlighting key points in the elucidation of characteristic clinical cases or not in the petvet clinic.
\end{abstract}

Keywords: Hemolytic anemia, Babesia spp., ixodidae ticks

\section{Introdução}

A Babesiose é uma doença causada por um protozoário Babesia canis e transmitida pelo carrapato Rhipicefalus sanguineus que é o parasita intermediário, o parasita se hospeda no hospedeiro definitivo e com a picada do carrapato (hospedeiro intermediário) é nesse momento inoculado no sangue do hospedeiro definitivo e invadem os glóbulos vermelhos se reproduzem e os destrói. Portanto, a doença se caracteriza por uma anemia hemolítica do tipo regenerativa. Outra forma de transmissão é através de transfusões sanguíneas de animais infectados (Vieira et al., 2013).

A babesiose canina é claramente uma das mais importantes infecções que acomete os cães por hemoprotozoários (protozoários que se reproduzem dentro das hemácias) originários do carrapato nas regiões tropical e subtropical do mundo. A Babesia canis e a Babesia gibsoni são as duas espécies capazes de infectar o cão (Brandão \& Hagiwara, 2002).

O tratamento pode ser bem sucedido dependendo de alguns fatores, como a imunidade do animal, e o tratamento suporte e todo o procedimento adequado a cada caso, como também pode ser uma doença que levará o animal a óbito (Vieira et al., 2013).

\section{Patogenia}

Toda a patogenia da babesia está relacionada à hemólise (quebra de hemácias), ocasionada por esta multiplicação do parasita no interior dos 
eritrócitos causando o rompimento. Com o rompimento das células parasitadas, além de causar anemia, ocorre liberação de hemoglobina, o que gera hemoglobinúria e bilirrubinemia. A fração indireta da bilirrubina, em grande quantidade, leva a uma sobrecarga do fígado, ocasionando icterícia, congestão hepática e esplênica, gerando hepatoesplenomegalia (Ettinger \& Feldman, 2004).

Em casos de infecções concomitantes de $B$. canis e E. canis, o cão demonstra uma severa anemia normocítica normocrômica, causada pela destruição de eritrócitos maduros e também ocorre o impedimento da eritropoiese, desenvolvendo uma doença muito grave, muitas vezes sendo fatal, principalmente em cães mais jovens (Silva et al., 2011).

\section{Aspectos clínicos}

Cães infectados podem apresentar quadro agudo com anorexia, apatia, diarreia, pneumonia, febre, hemoglobinúria, anemia branda a grave e icterícia, sendo que esta última nem sempre está presente, com curso de 3 a 10 dias. A evolução da doença pode levar a morte ou a lenta recuperação, que pode levar mais de um mês. Em alguns casos, pode haver o aparecimento de sintomas neurológicos, com extrema apatia ou agressividade, paralisia, desequilíbrio e ataxia. (Nelson \& Couto, 2015).

Os sinais clínicos do paciente acometido pela babesiose em seus três quadros da doença são apresentados na Tabela 1.

Tabela 1. Formas clínicas da Babesiose canina

\begin{tabular}{|c|c|c|}
\hline Hiperaguda & Aguda & Crônica \\
\hline Acidose Metabólica & Febre, hematúria e icterícia & Febre intermitente \\
\hline $\begin{array}{l}\text { Síndrome de resposta inflamatória } \\
\text { sistêmica }\end{array}$ & Letargia e anorexia & $\begin{array}{l}\text { Diminuição do rendimento em cães } \\
\text { atletas }\end{array}$ \\
\hline Hipóxia & Esplenomegalia & Diminuição do apetite \\
\hline Choque & Anemia Hemolítica & \\
\hline
\end{tabular}

(Nelson \& Couto, 2015).

\section{Diagnóstico}

O diagnóstico de babesiose é confirmado pela demonstração da presença dos protozoários no interior de eritrócitos. Os esfregaços sanguíneos são confeccionados com sangue periférico e corados por colorações do tipo Romanowsky, como Giemsa, Wright, Rosenfeld ou Diff- Quick. A presença de grandes organismos piriformes $(2,4$ x 5,0 $\mu \mathrm{m})$, comumente presentes aos pares, é indicativo de infecção por $B$. canis, enquanto microrganismos intracelulares singulares e menores $(1,0 \quad \mathrm{x} \quad 3,2 \mu \mathrm{m})$ provavelmente pertencerão à espécie $B$. gibsoni. Parasitemias muito baixas são características de $B$. canis, mas parasitemias de 5 a $40 \%$ caracterizam a infecção porB. gibsoni (Nelson \& Couto, 2015).

Entre os achados laboratoriais mais comuns estão a anemia regenerativa, hiperbilirrubinemia, bilirrubinúria, hemoglobinúria, trombocitopenia, acidose metabólica, azotemia e cilindros renais, sendo as principais anormalidades hematológicas observadas a anemia e a trombocitopenia (Moraes et al., 2016).
Em casos de babesiose canina, a anemia que é encontrada geralmente é normocítica normocrômica, de baixa intensidade nos primeiros dias após a infecção, tornando-se macrocítica, hipocrômica e regenerativa à medida que a moléstia progride. A reticulocitose é proporcional à gravidade da anemia. Anormalidades leucocitárias são observadas inconsistentemente, podendo ser: leucocitose, neutrofilia, neutropenia, linfocitose e eosinifilia. Animais adultos sorologicamente positivos, porém assintomáticos, podem não apresentar anormalidades hematológicas (Silva et al., 2011).

A babesiose também pode ser diagnosticada em situações de baixa parasitemia (casos de fase subaguda ou crônica) através do teste de ELISA. Assim como a imunofluorescência indireta, este teste permite a diferenciação entre animais doentes e animais nos quais os anticorpos são remanescentes de uma infecção precedente, não significa que a doença esteja ativa. Os testes sorológicos devem ser avaliados com cautela, e sempre em conjunto com os achados laboratoriais 
relevantes, como a contagem de plaquetas (trombocitopenia). (Silva et al., 2011).

Diagnósticos baseados na metodologia da biologia molecular são bem eficientes e tem sido muito usados, sendo que a metodologia usadas são ELISA e RIFI (imunofluorescencia indireta) nos quais são importantes para exposição do agente e não o grau de infecção que se encontra o paciente, quando está muito baixo o nível de parasitemia ou não detectável, e também quando o animal é assintomático. Já o PCR está sendo muito usado em estudos epidemiológicos (Silva et al., 2011).

A gravidade dos sintomas clínicos, bem como o comprometimento múltiplo de órgãos, é dependente da intensidade da hemólise promovida pelo hemoparasita, da patogenicidade da cepa envolvida, e de características de susceptibilidade relacionadas ao hospedeiro (Vieira et al., 2013).

\section{Tratamento}

O tratamento da babesiose em cães mais eficaz é o para o controle do parasita, moderação da resposta imune e tratamento sintomático, com sua eficácia estando relacionada à espécie de Babesia spp. a ser tratada e a disponibilidade de drogas específicas na região. Por exemplo, B. gibsoni apresenta uma menor resposta à terapia quando comparada com a B. canis, e também tem menor probabilidade de responder apenas à terapia sintomática (Silva et al., 2011).

O dipropionato de imidocarb causa a eliminação completa do agente do organismo animal, faz a inibição da perpetuação do estímulo antigênico, fazendo com que a proteção seja limitada, e os animais ficam suscetíveis a novas infecções. Nestas condições, a persistência de uma infecção residual seria desejável para que houvesse uma estimulação antigênica periódica, bem como a manutenção de um título adequado de anticorpos, os quais, em conjunto, promoveriam proteção prolongada. Por isso o uso doxiciclina, poderia ter essa finalidade, pois ela não causaria a extinção completa do agente, apenas limitaria a infecção em si. (Brandão \& Hagiwara, 2002).

O uso de fluido é importante para hidratação do animal e também para expandir o volume vascular, diminuindo a toxicidade, corrigindo os desequilíbrios eletrolíticos e ácido-básicos evitando assim uma acidose metabólica, perdidos durante a diarreia e os episódios de êmese. Caso o animal apresente infecções bacterianas secundárias, o uso de antibióticos é necessário. Em cães que estão muito acometidos com a doença pode ser necessário transfusões de sangue ou administração de bicarbonato na cetoacidose (Ettinger \& Feldman, 2004).

\section{Referências Bibliográficas}

Brandão, L. P. \& Hagiwara, M. K. 2002. Babesiose canina: revisão. Clínica Veterinária, 7, 50-59.

Ettinger, S. \& Feldman, E. 2004. Tratado de medicina interna veterinária: doenças do cão e do gato. Guanabara Koogan, Rio de Janeiro.

Moraes, L. F., Takahira, R. K., Golim, M. A. \& Baggio, M. S. 2016. Avaliação das alterações hemostáticas e do risco tromboembólico em cães com AHIM. Pesquisa Veterinaria Brasileira, 36, 405-411.

Nelson, R. W. \& Couto, C. G. 2015. Medicina interna de pequenos animais. Elsivier Editora, Amsterdan.

Silva, J. R., Meirelles, G. P., Zavilenski, R. B., Gravinatti, M. L., Silva, J. P. M., Bertéli, M. B. D., Martins, R. R., Ribeiro, M. G. \& Ribeiro, L. V. P. 2011. Avaliação do perfil renal de equinos submetidos ao tratamento com dipropionato de Imidocarb. Revista de Educação Continuada em Medicina Veterinária e Zootecnia, 9, 57-58.

Vieira, T. S. W. J., Vieira, R. F. d. C., Nascimento, D. A. G., Tamekuni, K., Toledo, R. d. S., Chandrashekar, R., Marcondes, M., Biondo, A. W. \& Vidotto, O. 2013. Serosurvey of tickborne pathogens in dogs from urban and rural areas from Paraná State, Brazil. Revista Brasileira de Parasitologia Veterinária, 22, 104-109.

\section{Article History}

Received 12 September 2016

Accepted 29 September 2016

Available on line 18 October 2016

License information: This is an open-access article distributed under the terms of the Creative Commons Attribution License 4.0, which permits unrestricted use, distribution, and reproduction in any medium, provided the original work is properly cite. 